Research Article

\title{
Knowledge, Awareness and Practices of Incident Cases of Dengue in Chandigarh
}

\author{
Ramanpreet Kaur', Harsh Rajvanshi ${ }^{2}$ \\ ${ }^{1}$ Medical Doctor, Medecins Sans Frontieres, Mumbai, India. \\ ${ }^{2}$ Program Officer, Malaria Elimination Demonstration Project, Foundation of Disease Elimination and Control of India, India. \\ DOI: https://doi.org/10.24321/0019.5138.201923
}

\section{I $\quad \mathbf{N} \quad \mathbf{F} \quad \mathbf{O}$}

\section{Corresponding Author:}

Ramanpreet Kaur, Medical Doctor, Medecins

Sans Frontieres, Mumbai, India.

E-mail Id:

drramanpreet84@gmail.com

Orcid Id:

https://orcid.org/0000-0002-4737-9287

How to cite this article:

Kaur R, Rajvanshi H. Knowledge, Awareness and Practices of Incident Cases of Dengue in Chandigarh. J Commun Dis 2019; 51(3): 28-32.

Date of Submission: 2019-07-08

Date of Acceptance: 2019-10-09

\section{$\begin{array}{llllllll}\mathbf{A} & \mathbf{B} & \mathbf{S} & \mathbf{T} & \mathbf{R} & \mathbf{A} & \mathbf{C} & \mathbf{T}\end{array}$}

Introduction: Dengue is an endemic disease in India. Epidemics occur every year with incidence rising every year. Since 2010, Chandigarh has seen Dengue epidemics every year but the toll of reported confirmed cases has been very low. A study was undertaken to assess knowledge, awareness and practices among those who had already been diagnosed with dengue and followed up multiple times by Multipurpose Health Workers (MPHWs) at their homes. This study was conducted when both authors were post-graduate scholars at the Department of Public Health at Manipal Academy of Higher Education.

Objective: To ascertain knowledge, awareness and practices regarding dengue among incident dengue cases of 2016 in Chandigarh.

Methods: Retrospective Cohort study was conducted among the incident cases of dengue reported in 2016. The line list of cases was obtained from health department. Each household was visited once and face to face interviews were conducted with those willing to participate from January 2017 to March 2017. Using a modified WHO (World Health Organisation) questionnaire, 149 interviews were completed and analysed using descriptive analytical tools.

Results: Data from the 149 interviews (57 males and 92 females) was used for primary analysis. Only $58.4 \%$ respondents were aware about dengue before diagnosis and $63.1 \%$ knew of its vector while only $10.1 \%$ were aware of the national programme and services available to them. Use of mosquito net was negligible (3.4\%), even in rural areas. Screens on doors and windows were more common in urban area of Chandigarh.

Conclusion: Since the study was conducted among incident cases, even after multiple visits conducted by MPHWs to the houses of these respondents, the knowledge regarding dengue was lower than expected.

Keywords: Knowledge, Awareness, Dengue Illness, Dengue

\section{Introduction}

Dengue is an endemic neglected tropical disease in India. Epidemics occur every year accompanied with a continuous rise in incidence. In 2012, it was ranked as the most important mosquito borne viral disease. ${ }^{1}$ India saw the rise in Dengue cases from 28292 cases in 2010 to 129166 in $2016 .^{2}$

Since 2010, Chandigarh has seen Dengue epidemics every 
year. In the year 2014, only 13 confirmed cases of Dengue were reported, followed by a sharp rise to 966 and 1246 cases 2015 and 2016, respectively. ${ }^{2}$

Lack of awareness, increased human population, travel and rapid urbanization has resulted in increased Dengue transmission. ${ }^{3}$ Many studies have been done to study the awareness and practices amongst different socioeconomic groups in different settings. The studies have concluded that the knowledge among the general public remains unsatisfactory in different socioeconomic groups. The same have been discussed in detail later in this paper. Therefore, this study was undertaken to assess Knowledge, Awareness and Practices (KAP) amongst those who had already been diagnosed and treated for Dengue fever accompanied with multiple follow up visits by Multipurpose Health Workers (MPHWs) at their homes. It will be interesting to see the effect of the exposure of illness and repeated follow ups on the KAP status of an urban community.

\section{Objective}

To ascertain Knowledge, Awareness and Practices (KAP) regarding Dengue amongst incident Dengue cases of 2016 in Chandigarh.

\section{Materials and Methods}

A retrospective cohort study was designed to determine the knowledge, awareness and preventive practices amongst the confirmed cases of Dengue in Chandigarh in the year 2016. The study period was January to June 2017. The data collection period for the study was 3 months, i.e. January to March 2017.

A list of confirmed cases was obtained from the Health Department, Union Territory of Chandigarh after taking due permission. The basis on which cases were labelled as Dengue by the municipal health office of Chandigarh UT was: a case compatible with the clinical description of Dengue fever with at least one of the following:

- Demonstration of Dengue virus antigen in serum samples by NS1 ELISA

- Demonstration of IgM antibody titre by ELISA positive in single serum sample.

The list was then divided as per area and those not fitting in inclusion criteria were removed from the list. Households with cases above 18 years or age, who lived in Chandigarh UT and consented to the study, were included. In households reporting multiple cases, only one case was included in the study.

The visits were conducted in coordination with the Multipurpose Health Workers (MPHWs) under National Rural Health Mission (NRHM), Chandigarh. The MPHWs of that area were informed beforehand of the visit. The household of each confirmed case was visited by interviewer.
The interview was conducted after taking written informed consent from each respondent. Each interview and survey took 30 to 45 minutes to complete. For each interview conducted, a separate questionnaire form was filled. The questionnaire used was a modified WHO household survey.

Every single household was visited and interviewed by the Principal Investigator accompanied by an MPHW. Out of total 887 cases, address could be traced for 666 excluding those who were under the age of 18 (199) and those where address could not be traced (22). A total of 149 households with cases were available at the time of our visit for interview. The 149 respondents were questioned about their knowledge and awareness regarding Dengue, and preventive practices followed by them.

Ethical clearance for the study was procured from the Manipal University Ethical Committee.

The data was analysed using SPSS version 21.

\section{Result}

Almost half of the respondents (51\%) 76 of the 149 resided in urban area, $70(47 \%)$ resided in rural area (including slums) of Chandigarh. There were 126 cases of Dengue Fever (DF) and 23 cases of severe Dengue among the respondents. Out of the 23 severe Dengue cases, 15 were reported from urban area, 8 from rural and none in slums while DF cases were distributed almost equally in urban and rural areas. The mean age of respondents was 36.11 years ( \pm 14.494 SD) and ranged from 19 to 80 years. The highest numbers of cases were seen in the age group 19 to 30 years. Out of the 149 respondents, 82 (55\%) were educated up to secondary school ( $12^{\text {th }}$ class) while the remaining 67 (45\%) had a college education. There were 51 graduates and 16 postgraduates amongst those who went to college. Amongst the 82,18 were illiterate. Respondents who were unemployed made up $63.1 \%$ of the sample (94 out of 149). This group included homemaker (49.3\%), students (13.4\%) and retirees/pensioners (3.4\%). The remaining 55 (36.9\%) were employed (Table 1).

Indoor Residual Spray (IRS) was done in 128 (85.9\%) of the households after they were diagnosed with Dengue. Mosquito net as personal protection was used by only five $(3.4 \%)$ of the 149 respondents. All five nets were reportedly bought from a shop selling clothing material and were not treated with long lasting insecticides. On an average, the nets were bought 12.80 ( \pm 6.573 SD) months ago. Use of mosquito repellents was reported by 136 households, out which only 129 (90.8\%) households were considered (households using anti mosquito sprays were not considered as the effect is not comparable to other repellents). Liquid electric repellent was the choice for 115 (77.2\%) households, followed by mosquito repellent coils ( 9 households) and repellent mats ( 5 households). Remaining 
13 households did not use any repellents. Repellents were used most commonly only at night as noted in 95 (63.8\%) respondents, 14 (9.4\%) used the repellents all day, 11 (7.4\%) households used the repellent at evening and night both, while only $4(2.7 \%)$ used it in the evening and $2(1.3 \%)$ households used repellents during day (Table 2 ).

Table I.Distribution as per characteristics of respondents $(N=149)$

\begin{tabular}{|c|c|}
\hline Characteristics & $\begin{array}{c}\text { Frequency } \\
\text { n (\%) }\end{array}$ \\
\hline \multicolumn{2}{|l|}{ Age (in years) Mean \pm SD $(36.11 \pm 14.494)$} \\
\hline 19-30 & $65(43.7)$ \\
\hline $30-45$ & $30(20.1)$ \\
\hline $45-60$ & $37(24.8)$ \\
\hline $60-80$ & $17(11.4)$ \\
\hline \multicolumn{2}{|l|}{ Area of living } \\
\hline Urban & $76(51)$ \\
\hline Rural & $73(49)$ \\
\hline \multicolumn{2}{|l|}{ Type of dengue } \\
\hline DF & $126(84.6)$ \\
\hline DHF/ Severe Dengue & $23(15.4)$ \\
\hline \multicolumn{2}{|l|}{ Gender of respondents } \\
\hline Male & $57(38.3)$ \\
\hline Female & $92(61.7)$ \\
\hline \multicolumn{2}{|l|}{ Education of respondent } \\
\hline Illiterate & $18(12.1)$ \\
\hline Up to $5^{\text {th }}$ & $18(12.1)$ \\
\hline Up to $10^{\text {th }}$ & $20(13.4)$ \\
\hline Up to $12^{\text {th }}$ & $26(17.4)$ \\
\hline Graduate & $51(34.2)$ \\
\hline Postgraduate & $16(10.7)$ \\
\hline \multicolumn{2}{|l|}{ Employment } \\
\hline Unemployed & $94(63.1)$ \\
\hline Employed & 55 (36.9) \\
\hline
\end{tabular}

Table 2.Anti mosquito measures used by respondents $(\mathbf{N}=149)$

\begin{tabular}{|c|c|}
\hline Characteristics & Frequency $\mathbf{n}$ (\%) \\
\hline Use of mosquito nets & \\
\hline Yes & $5(3.4)$ \\
\hline No & $144(96.6)$ \\
\hline Indoor residual spray & \\
\hline Yes & $128(85.9)$ \\
\hline No & $21(14.1)$ \\
\hline
\end{tabular}

\begin{tabular}{|c|c|}
\hline $\begin{array}{c}\text { Type of mosquito repellent used at } \\
\text { home }\end{array}$ & \\
\hline Coil & 9 \\
\hline Mat & 5 \\
\hline Liquid & 115 \\
\hline Spray & 7 \\
\hline None & 13 \\
\hline Time at which mosquito repellent \\
is used & \\
\hline All day & $14(9.4 \%)$ \\
\hline During day time & 2 \\
\hline Evenings only & 4 \\
\hline Night time only & $95(63.8 \%)$ \\
\hline Evening onwards & 11 \\
\hline Once a week & 10 \\
\hline Screens on doors and windows & $110(73.8)$ \\
\hline Yes & $39(26.2)$ \\
\hline No & \\
\hline
\end{tabular}

Table 3.Awareness among respondents $(N=149)$

\begin{tabular}{|c|c|}
\hline Characteristics & $\begin{array}{c}\text { Frequency } \\
\text { n (\%) }\end{array}$ \\
\hline \multicolumn{2}{|l|}{ Awareness of dengue before getting ill } \\
\hline Yes & $87(58.4)$ \\
\hline No & $62(41.6)$ \\
\hline \multicolumn{2}{|l|}{ Aware that Dengue is spread by mosquito } \\
\hline Yes & $94(63.1)$ \\
\hline No & 55 (36.9) \\
\hline \multicolumn{2}{|l|}{$\begin{array}{c}\text { Aware about national programme for } \\
\text { Dengue control }\end{array}$} \\
\hline Yes & $15(10.1)$ \\
\hline No & 134 (89.9) \\
\hline \multicolumn{2}{|l|}{ Aware of any preventive measures } \\
\hline Yes & $89(59.7)$ \\
\hline No & $60(40.3)$ \\
\hline \multicolumn{2}{|l|}{ Risk of dengue only in rainy season } \\
\hline Agree & $25(16.8)$ \\
\hline Don't know & $45(30.2)$ \\
\hline Disagree & $29(19.5)$ \\
\hline Strongly disagree & $50(33.6)$ \\
\hline \multicolumn{2}{|l|}{$\begin{array}{l}\text { Aware of separation of garbage before } \\
\text { disposal }\end{array}$} \\
\hline Yes & $39(39.2)$ \\
\hline No & $110(73.8)$ \\
\hline
\end{tabular}


Table 4. Types of preventive measures known to respondents $(\mathbf{N}=149)$

\begin{tabular}{|c|c|}
\hline Type of Preventive Measure known & $\begin{array}{c}\text { Frequency } \\
\mathbf{n}(\%)\end{array}$ \\
\hline $\begin{array}{c}\text { Clothing, avoid water stagnation, } \\
\text { repellents }\end{array}$ & $12(8.1)$ \\
\hline Repellents only & $28(18.8)$ \\
\hline Clothing only & $13(8.7)$ \\
\hline Avoid water stagnation only & $14(9.4)$ \\
\hline Cleanliness only & $2(1.3)$ \\
\hline Clothing, repellents & $7(4.7)$ \\
\hline Repellents, cleanliness & $2(1.3)$ \\
\hline Water stagnation, repellents & $6(4.0)$ \\
\hline Clothing, water stagnation & $5(3.4)$ \\
\hline
\end{tabular}

Table 5.Type of preventive measure known $(n=89)$

\begin{tabular}{|c|c|}
\hline Type of preventive measure known & $\begin{array}{c}\text { Frequency } \\
\mathbf{n}(\%)\end{array}$ \\
\hline Repellents & 55 \\
\hline Avoid Water Stagnation & 37 \\
\hline Clothing & 37 \\
\hline Cleanliness & 4 \\
\hline
\end{tabular}

A total of 87 (58.4\%) respondents were aware about Dengue before getting ill and $62.1 \%$ of these were respondents with a college education. A total of 94 (63.1\%) respondents knew that Dengue is spread by mosquitoes and $62.8 \%$ of these respondents had college education. Most respondents
(89.9\%) were unaware that there was a national programme aimed at controlling Dengue, under which they are eligible for services and $58.2 \%$ of these respondents had only been to secondary school (Table 3).

Awareness about preventive measures was found in 89 (59.7\%) of the respondents, $60.7 \%$ of which had been educated up to college level. Table 4 shows the different types of preventive measures known and reported by the respondents. Respondents reported knowing either three measures or two or one measure. The three measures reported were covered clothing, use of repellents and avoiding water stagnation, and were known to 12 (8.1\%) of the 89 respondents. Two types of measures were reported by 20 respondents; only one known measure was reported by 57 respondents. Only repellents as the form of prevention known were reported by 28 of the 57 respondents. The repellents reported were liquid electric repellents, coils, mats, sprays and nets. A total of 14 respondents knew that avoiding water stagnation alone can reduce mosquito population and 13 reported that wearing full sleeves and covered clothing can prevent mosquito bites (Table 5).

All respondents were asked to respond to the statement 'Risk of Dengue is ONLY during the rainy season'. The responses were strongly agreeing, don't know, disagree and strongly disagree. None of the participants strongly agreed with the statement. Out of 149, 50 (33.6\%) respondents strongly disagreed, while $45(30.2 \%)$ did not know if the statement was true or not. Also, $73.8 \%$ respondents did not know that garbage should be separated before disposal out of which more than half $(59.1 \%)$ were educated up to secondary school.

Table 6.Awareness of Dengue amongst respondents and education status $(\mathbf{N}=149)$

\begin{tabular}{|c|c|c|c|c|c|}
\hline & & \multicolumn{4}{|c|}{ Education level of respondent } \\
\hline & \multicolumn{2}{|c|}{ Up to Secondary School } & \multicolumn{2}{|c|}{ College } & \\
\hline \multirow{2}{*}{ Aware of Dengue illness before getting sick } & Yes & 33 & $37.9 \%$ & 54 & $62.1 \%$ \\
\hline & No & 49 & $79.0 \%$ & 13 & $21.0 \%$ \\
\hline \multirow{2}{*}{ Aware that it is spread by mosquito } & Yes & 35 & $37.2 \%$ & 59 & $62.8 \%$ \\
\hline & No & 47 & $85.5 \%$ & 8 & $14.5 \%$ \\
\hline \multirow{2}{*}{ Aware of national programme for Dengue } & Yes & 4 & $26.7 \%$ & 11 & $73.3 \%$ \\
\hline & No & 78 & $58.2 \%$ & 56 & $41.8 \%$ \\
\hline \multirow{2}{*}{ Aware of preventive measures } & Yes & 35 & $39.3 \%$ & 54 & $60.7 \%$ \\
\hline & No & 47 & $78.3 \%$ & 13 & $21.7 \%$ \\
\hline \multirow{4}{*}{ Risk of dengue only in rainy season } & Agree & 14 & $56.0 \%$ & 11 & $44.0 \%$ \\
\hline & Don't Know & 35 & $77.8 \%$ & 10 & $22.2 \%$ \\
\hline & Disagree & 14 & $48.3 \%$ & 15 & $51.7 \%$ \\
\hline & Strongly Disagree & 19 & $38.0 \%$ & 31 & $62.0 \%$ \\
\hline \multirow{2}{*}{ Aware of garbage separation } & Yes & 17 & $43.6 \%$ & 22 & $56.4 \%$ \\
\hline & No & 65 & $59.1 \%$ & 45 & $40.9 \%$ \\
\hline
\end{tabular}




\section{Discussion}

Respondents who lived in urban areas and had a college education showed more awareness to Dengue illness and its spread by mosquitoes as compared to those who lived in rural areas and had education up-to secondary school. Despite multiple visits conducted the field workers, there was very poor awareness regarding the national programme for Dengue control and services offered by the government, However, it is worth noting that most respondents disagreed that rainy season is the only season for Dengue.

Malhotra et al did a KAP study in rural and slum population of Chandigarh in 2013. Their study showed that awareness about Dengue fever was more in rural areas as compared to slums. A total of $72.62 \%$ respondents knew that mosquito was the cause of Dengue transmission. ${ }^{4}$ In another study done by Acharya et al in an urban settlement area of south Delhi, 90\% were reportedly aware of Dengue illness (5). $67 \%$ respondents knew about Dengue illness in Thailand as reported by a study done by Swaddiwu Dhipong et al. ${ }^{6}$ Our study concludes that awareness regarding the illness and the vector was unsatisfactory, and was associated with level of education of respondents.

Malhotra $G$ et al. did a KAP study in rural and slum population of Chandigarh in 2013. Liquid vaporisers and coils were reported to be the most commonly used repellents and all these repellents were used at night time only. Nets were used by only $6.25 \%$ of the participants. $5.2 \%$ respondents did not use any kind of repellent. Their study reports that there is no use of insecticide sprays, professional pest control and screening of doors and windows as preventive measures in the rural or slum area of Chandigarh. ${ }^{4}$ While we found that liquid repellents use was higher than coil use and use of nets continues to be very poor among the households of confirmed cases. It can be argued that use of nets may not be that effective as dengue mosquito bites during the day and nets are used at night. However, use of screens on doors and windows in both urban and rural areas was very high.

Though Indoor residual spray is not recommended for Dengue, it was found to be done in $85.9 \%$ households, apparently after they had been diagnosed with Dengue. ${ }^{7}$

\section{Conclusion}

In conclusion, we note that the knowledge regarding Dengue is not what would be expected. This is a clear indicator that the method of delivery of information needs to be enhanced through training and retraining of health workers, along with monitoring of these visits at regular intervals by supervisors. Community participation can be enhanced by reinforcement of messages through various media. Information pamphlets should be supplied to those whose houses are visited by the health workers.

\section{Limitations}

The list of cases received from the Chandigarh UT at the time of beginning of this study was 887 cases which had, subsequently, been revised to 1246 . Hence, we could not include about a third of the total cases. Data was collected between 9 am and 3 pm, working hours of MPHWs. Thus, interviews were conducted only of those available at home.

\section{Conflict of Interest: None}

\section{References}

1. Global strategy for dengue prevention and control, 2012-2020. $1^{\text {st }}$ ed. World Health Organization, Geneva, Switzerland. 2012.

2. Dengue cases and deaths in the country since 2010: Dte. of National Vector Borne Disease Control Programme, MoHFW, GOI, 2016. Cited 2017 March 20. Available from: http://nvbdcp.gov.in/den-cd.html.

3. Gubler DJ, Clark GG. Dengue/dengue hemorrhagic fever the emergence for a global health problem. Emerg Infect Dis 1995; 1(2): 55-57.

4. Malhotra G, Yadav A, Dudeja P. Knowledge, awareness and practices regarding dengue among rural and slum communities in North Indian city, India. IJCMPH 2014; 3(3): 295-299.

5. Acharya A, Goswami K, Srinath S et al. Awareness about dengue syndrome and related preventive practices amongst residents of an urban resettlement colony of south Delhi. Journal of Vector Borne Diseases 2005; 42(3): 122.

6. Swaddiwu dhipong $W$, Lerdlukanavonge $P$, Khumklam $P$ et al. A survey of knowledge, attitude and practice of the prevention of dengue hemorrhagic fever in an urban community of Thailand. Shock 1992; 5: 1-2.

7. Dengue Vector Control Measures: Dte. Of National Vector Borne Disease Control Programme, MoHFW, GOI, 2016. Available from: http://www.nvbdcp.gov. in/dengue12.html. 